\title{
Commentary on A multinational, multicenter, randomized, double-blinded, placebo-controlled trial to evaluate the efficacy of cyclical topical wound oxygen therapy (TWO2) in the treatment of chronic diabetic foot ulcers: The TWO2 study
}

\author{
Robert Frykberg* \\ Diabetic Foot Consultants, Midwestern University, Glendale, AZ, USA
}

\section{Commentary}

Topical Oxygen therapy (TOT) in various forms has been used for the treatment of chronic wounds for over fifty years [1-6 ]. Its effectiveness has been disputed despite many positive clinical and animal reports attesting to its benefits towards promoting wound healing. Various delivery mechanisms have been utilized in this regard including continuous delivery of oxygen (CDO) under low or very low Oxygen tensions or Cyclical Pressurized topical delivery generally within a localized extremity chamber. Hyperbaric Oxygen Therapy (HBOT) proponents have long criticized the ability of TOT to have a meaningful effect on wound repair in the absence of systemic delivery of Oxygen [7]. Despite the many inconsistent wound healing clinical studies of HBOT itself [8-13], most criticisms of TOT, notwithstanding the skepticism mentioned above, are due to an extremely limited number of robust high-quality investigations. We therefore performed a study to assess the efficacy of multi-modality cyclical pressure Topical Wound Oxygen (TWO2) homecare therapy in healing refractory diabetic foot ulcers (DFU) that had failed to heal with standard of care (SOC) alone [14].

\section{Research Design And Methods}

Patients with diabetes and chronic DFUs that had failed to improve with four weeks of standard clinical care were screened for enrollment. After informed consent the patients entered a two week run-in period of optimal standard of care consisting of uniform offloading, debridement, and dressings. Although 25 percent of these patients healed $>30 \%$ of their wound area and were subsequently excluded from the trial, eligible subjects were then randomized (double blind) to either active TWO2 therapy or sham control therapy, both in addition to optimal SOC. The primary outcome was the percentage of ulcers in each group achieving $100 \%$ healing at 12 weeks. A Group Sequential Design was utilized for the study with three predetermined analyses and hard stopping rules once 73,146 and ultimately 220 patients completed the 12-week treatment phase.

\section{Results}

At the first analysis point the active TWO2 arm was found to be superior to the sham arm, with a closure rate of $41.7 \%$ compared with $13.5 \%$. This difference in outcome produced an odds ratio [OR] of 4.57, [97.8\% CI 1.19, 17.57], $\mathrm{p}=0.010$. After adjustment for University

of Texas Classification (UTC) ulcer grade the odds ratio [97.8\% CI] increased to $6.00[1.44,24.93], \mathrm{p}=0.004$. Cox proportional hazards modelling, also after adjusting for UTC grade, demonstrated more than 4.5 times the likelihood to heal DFUs over 12 weeks compared to the sham arm with a hazard ratio [HR] of 4.66 (97.8\% CI 1.36, 15.98), $\mathrm{p}=0.004$. The Kaplan-Meier curve shown in the Figure clearly shows the separation between groups throughout the active phase of the study. Larger wounds $(>4 \mathrm{~cm} 2)$ also showed significant improvement with the active therapy with an absolute reduction in ulcer area (SD) from baseline of $4.12(1.51) \mathrm{cm}^{2}$ compared to a $1.34(1.18) \mathrm{cm}^{2}$ increase for the sham arm $[t(d f)=2.85(8), p=0.021]$. Therapy and Offloading compliance exceeded $95 \%$ for both groups.

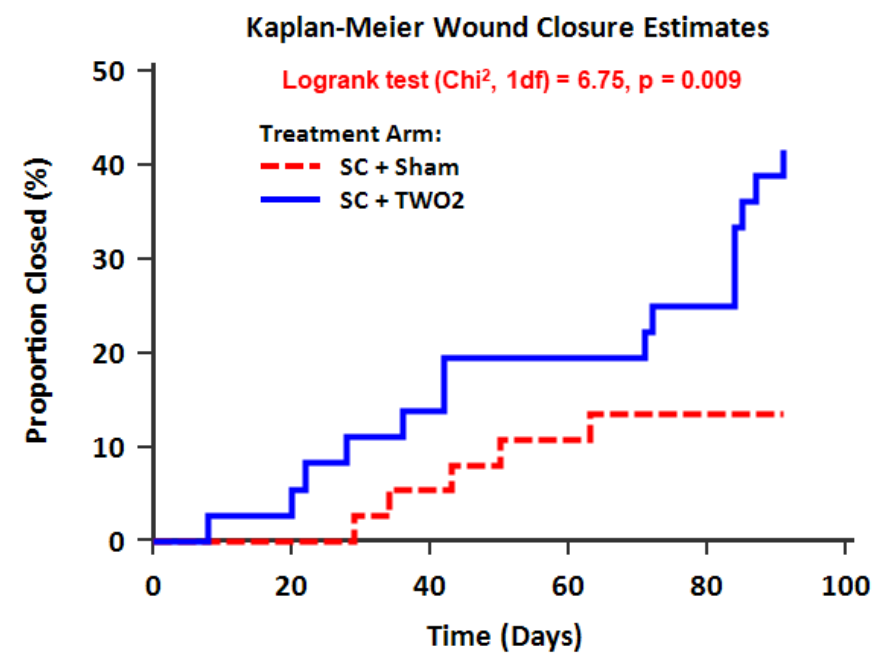

Figure 1. Kaplan-Meier curve showing the separation between study groups throughout the 12 -week trial. Solid line represents actively treated group and hashed line indicates the sham treated group

*Correspondence to: Robert Frykberg, Diabetic Foot Consultants, Midwestern University, Glendale, AZ, USA, E-mail: rgfdpm@diabeticfoot.net

Received: August 24, 2019; Accepted: September 20, 2019; Published: September 23, 2019 
Frykberg R (2019) Commentary on A multinational, multicenter, randomized, double-blinded, placebo-controlled trial to evaluate the efficacy of cyclical topical wound oxygen therapy (TWO2) in the treatment of chronic diabetic foot ulcers: The TWO2 study

At 12 months post enrollment, $56 \%$ of active arm ulcers were closed compared to $27 \%$ of the sham arm ulcers $(p=0.013)$ and there was a six fold difference in wound recurrence between groups, favouring the TWO2 treated patients. .

\section{Conclusions}

This sham-controlled, double blind RCT demonstrates that, at both 12 weeks and 12 months, adjunctive cyclical pressurized TWO2 therapy was superior in healing chronic DFUs compared to optimal SOC alone. In contrast to recently reported systemic HBOT studies, this robust double blinded, sham controlled trial provides evidence to support use of this adjunctive cyclical pressurized topical oxygen therapy for chronic DFUs.

\section{References}

1. Fischer BH (1969) Topical hyperbaric oxygen treatment of pressure sores and skin ulcers. Lancet 2: 405-409.

2. Gordillo GM, Schlanger R, Wallace WA, Bergdall V, Bartlett R, et al. (2004) Protocols for topical and systemic oxygen treatments in wound healing. Methods Enzymol 381: 575-585. [Crossref]

3. Kalliainen LK, Gordillo GM, Schlanger R, Sen CK (2003) Topical oxygen as an adjunct to wound healing: a clinical case series. Pathophysiology 9: 81-87. [Crossref]

4. Leslie CA, Sapico FL, Ginunas VJ, Adkins RH (1988) Randomized controlled trial of topical hyperbaric oxygen for treatment of diabetic foot ulcers. Diabetes care 11: 111-115. [Crossref]

5. Tawfick WA, Sultan S (2013) Technical and clinical outcome of topical wound oxygen in comparison to conventional compression dressings in the management of refractory nonhealing venous ulcers. Vasc Endovasc Surg 47: 30-37. [Crossref]
6. Woo KY, Coutts PM, Sibbald RG (2012) Continuous topical oxygen for the treatment of chronic wounds: a pilot study. Adv Skin Wound care 25: 543-547. [Crossref]

7. Feldmeier JJ, Hopf HW, Warriner RA 3rd, Fife CE, Gesell LB, et al. (2005). UHMS position statement: topical oxygen for chronic wounds. Undersea Hyperb Med 32: 157168. [Crossref]

8. Fedorko L, Bowen JM, Jones W, Oreopoulos G, Goeree R, et al. (2016) Hyperbaric Oxygen Therapy Does Not Reduce Indications for Amputation in Patients With Diabetes With Nonhealing Ulcers of the Lower Limb: A Prospective, Double-Blind, Randomized Controlled Clinical Trial. Diabetes care 39: 392-399. [Crossref]

9. Gottrup F, Dissemond J, Baines C, Frykberg R, Jensen PØ, et al. (2017) Use of Oxygen Therapies in Wound Healing. J Wound Care 26: S1-1S43. [Crossref]

10. Londahl M, Katzman P, Nilsson A, Hammarlund C (2010) Hyperbaric oxygen therapy facilitates healing of chronic foot ulcers in patients with diabetes. Diabetes Care 33 998-1003. [Crossref]

11. Margolis DJ, Gupta J, Hoffstad O, et al. (2013) Lack of effectiveness of hyperbaric oxygen therapy for the treatment of diabetic foot ulcer and the prevention of amputation: a cohort study. Diabetes care 36: 1961-1966. [Crossref]

12. Santema KTB, Stoekenbroek RM, Koelemay MJW, Reekers JA, van Dortmon LMC, et al. (2018) Hyperbaric Oxygen Therapy in the Treatment of Ischemic LowerExtremity Ulcers in Patients With Diabetes: Results of the DAMO2CLES Multicenter Randomized Clinical Trial. Diabetes Care 41: 112-119. [Crossref]

13. Zamboni WA, Wong HP, Stephenson LL, Pfeifer MA (1997) Evaluation of hyperbaric oxygen for diabetic wounds: a prospective study. Undersea Hyperb Med 24: 175-179. [Crossref]

14. Frykberg RG, Franks PJ, Edmonds M, Brantley JN, Téot L, et al. (2019) A Multinational, Multicenter, Randomized, Double-Blinded, Placebo-Controlled Trial to Evaluate the Efficacy of Cyclical Topical Wound Oxygen Therapy (TWO2) in the Treatment of Chronic Diabetic Foot Ulcers: The TWO2 Study. Diabetes Care. [Crossref]

Copyright: (C2019 Frykberg R. This is an open-access article distributed under the terms of the Creative Commons Attribution License, which permits unrestricted use, distribution, and reproduction in any medium, provided the original author and source are credited. 